\title{
Evaluation of Radiological Health Risk Associated with Indian Tiles Available in Nigerian Markets
}

\author{
Adewoyin Olusegun Oladotun ${ }^{1, *}$, Omeje Maxwell ${ }^{1}$, Joel Emmanuel Sunday ${ }^{1}$, Mojisola Rachael Usikalu ${ }^{1}, Z^{2}$ Idi Embong $^{2}$, Alam Saeed $^{3}$ \\ ${ }^{1}$ Department of Physics, College of Science and Technology, Covenant University, P.M.B 1023, Ota, Ogun State, 110253, Nigeria
}

${ }^{2}$ Faculty of Science, Technology and Human Development, Universiti Tun Hussein Onn Malaysia, Parit Raja, Batu Pahat, Johor, 86400 Malaysia

${ }^{3}$ Division of Science and Technology, University of Education Township Lahore, 42000, Pakistan

\begin{tabular}{l} 
A R T I C L E I N F O \\
\hline Article history: \\
Received: 10 September, 2020 \\
Accepted: 11 February, 2021 \\
Online: 28 May, 2021
\end{tabular}

Keywords:

Indian tiles

Gamma spectroscopy

Potential health risk

Internal hazard index

External hazard index

\begin{abstract}
A B S T R A C T
Seven imported Indian tiles available in the Nigerian markets were investigated in this study to determine their radiological health hazards on users. Gamma spectroscopy was used for the analysis. The calculated radiological variables such as the dose rate, radium equivalent, internal and external hazard indices, gamma index, annual effective dose and the corresponding alpha index were used to determine the potential health risks on people exposed to these building tiles. The average activity concentration of ${ }^{226} \mathrm{Ra},{ }^{232} \mathrm{Th}$ and ${ }^{40} \mathrm{~K}$ were found to be 68.03, 84.79 and $620.89 \mathrm{~Bq} / \mathrm{kg}$ respectively. These results were observed to be greater than the world recognized average safe boundary for building purposes. Similarly, the dose rate for all investigated tiles ranged between 59.14 and 154.65. This also revealed much higher values than the recommended standard except for GPI which recorded a lower result. However, the mean result of the radium activity equivalent in all the samples investigated was noted to be $237.09 \mathrm{~Bq} / \mathrm{kg}$. Both internal and external hazard indices reported much lower results than the recommended safe limit in all the tiles. Similarly, the gamma activity, the annual effective dose, and the alpha indices reported results that are within the safe limit. Therefore, it can be concluded that Indian tiles present in Nigerian market do not pose any health risk to users.
\end{abstract}

\section{Introduction}

One of the environmental challenges that is a concern in every part of the world is the exposure of man to radiation. The undue exposure of man to this radiation have been noted to result in adverse medical effect on human.[1]. Natural occurrences and man-made activities have had significant impacts on the level of radiation available in our environment. Therefore, satisfactory and acceptable information of the level of exposure from both man-made and natural radioactivity sources is very crucial. Researches have revealed that the earth crust is composed of different materials including materials that contain a relatively low concentration of naturally occurring radionuclides. It has also been noted in recent studies that water and soil polluted with radionuclides could be threats to the public health as well as the environment [2]. Further research revealed that the average

*Corresponding Author: Adewoyin Olusegun Oladotun, segadot@yahoo.com www.astesj.com

https://dx.doi.org/10.25046/aj060330 standard for indoor effective dose due to gamma rays from building materials is about $0.4 \mathrm{mSv}$ per annum [1] and [3]. The major contributors identified for exposures to radiation of natural sources include radioactive nuclides present in the earth's crust, natural radionuclides present in human body (taken in through diets) and cosmic ray particles incident on the earth [1]. People are more prone to radiation exposure by staying indoors as the radioactive materials are more concentrated indoor than outdoor. This is because naturally occurring radioactive materials are present in the crust, ceilings, floors and concrete walls of schools, homes, offices and malls, where occupants spend a lot of time [4] and [5]. Moreover, the concentration of the radioactive materials is more in an indoor environment, when the ventilation is poor.

Generally, building materials are made from rocks and soil, which originate from the earth crust, while some are developed from a mixture of industrial by products[6] and [7]. Therefore, 
they have very high tendency of containing more radioactive substances such as $238 \mathrm{U}$ and $232 \mathrm{Th}$ series and natural $40 \mathrm{~K}$, which are naturally part of the raw materials for building materials $[3[$, [5] and [8]. Also, every stage of construction of a building requires the use of soil or rocks and the land on which a building is sited constitute a major proportion of radioactive materials [9] and [10]. The foregone further established why the indoor concentration of these substances may be very high [9-11]. The availability of naturally occurring radioactive materials (NORMs) in building materials is the cause for the internal and external exposures of radiation to individuals staying in buildings [12-16]. Similarly plant cultivation and the introduction of various chemical fertilizers to aid the farming yield could expose consumers to more radiation. This is because the application of fertilizers to soil, used for farming purposes, may increase its radionuclide contents beyond proportion. Thus, man becomes unduly exposed when feeding on plants cultivated on these kind of lands because of exchange of nutrients between the soil and the plants [17]. Therefore, feeding on some of these plants, especially those that require more proportion of these chemical based fertilizers to germinate would expose man to radioactive substances.

Proper consideration of the above makes it clear that there is no escape for man from radiation exposure, the consolation is that adequate efforts must be made to control exposure so as to prevent the associated health risk. It is on this note that this research was conducted on the commonly purchased building tiles available in Nigeria so as to evaluate and ascertain the concentration of radionuclides in the tiles and also, to estimate the possible health risk of exposure to the people that are often in contact with them.

\section{Materials and Methods}

\subsection{Preparation of Samples}

Seven (7) different samples of tiles Indian branded tiles that are commonly available and purchased for building construction purposes in Nigerian markets were studied in this research (Table 1). The tiles were transported to the geological laboratory at Obafemi Awolowo University, Ile Ife in Osun State Nigeria for preparation. The tiles were prepared by first labelling and assigning sample identity to each pack. Second on the line of preparation involved breaking all the tile samples into smaller pieces for the next stage of processing using the Pascall Engineering Lab milling machine. The samples were crushed to size that would be easy for pulverization. One of the precautions observed at this stage was that, the crusher or lab milling machine was adequately cleaned using a pressure blower (Wolf power tools, made in London with serial and type and numbers 978 A and 8793 respectively) after each tile sample was crushed to prevent erroneous mixture of the samples. Furthermore, each sample of crushed tiles was pulverized by completely grinding them into fine powder using the disk "grinder/pulverizer" by Christy and Norris Limited. As done with the crusher, the pulverizer was thoroughly cleaned and blown by a pressure blower, after each sample was grinded in order to avoid cross contamination of the samples. After this stage, a very fine powder of each sample was obtained, this was sieved using a $250 \mu \mathrm{m}$ sieve size for the purpose of homogeneity. A measured quantity of 200 $\mathrm{g}$ of each sieved sample was first packaged in a high density polyethylene bottles (HDPB) before it was transferred to $500 \mathrm{~mL}$ size of Marinelli beakers for radioactivity study. The bottles had been earlier washed with detergent and thoroughly rinsed with ordinary water from borehole and finally rinsed with distilled water.

Table 1: Tables containing the list of tile samples imported from India

\section{s/n Sample Name}

1 Rose Bite India

2 Tam Brown India

3 Goodwill Vitrified Tile

4 Green Pearl India

5 Goodwill Super Polish Porcelain Tiles

6 Black Galaxy India

7 Blue Pearl India
Sample ID

RBI

TBI

GVI

GPI

GSPPT

BGI

BPI

\subsection{Gamma Spectrometric Analysis of the Selected Samples}

The purchased samples of Indian tiles available in the Nigerian market were prepared in accordance to the IAEA TRS295 [18]. The prepared samples were packaged in a plastic beaker container and were sealed for twenty-eight days for secular equilibrium, so that the parent radionuclide would be equal to the daughter. The samples were analyzed at the Nuclear laboratory of Universiti Malaysia with the use of High Purity Germanium detector using the approach engaged by [7] and [9-11].

\section{Results and Discussion}

\subsection{Determination of Radioactivity Concentration}

The radioactivity concentrations of ${ }^{226} \mathrm{Ra},{ }^{232} \mathrm{Th}$, and ${ }^{40} \mathrm{~K}$ for samples of produced in India and their corresponding average values are presented in Table 2 .

The result of the activity concentrations of radionuclide contents in the samples of Indian tiles available in Nigeria ranged between 18.68 and $98.3 \mathrm{~Bq} / \mathrm{kg}$ for ${ }^{226} \mathrm{Ra}, 42.1$ and $104.28 \mathrm{~Bq} / \mathrm{kg}$ for ${ }^{232} \mathrm{Th}$ and 181.4 and $871.0 \mathrm{~Bq} / \mathrm{kg}$ for ${ }^{40} \mathrm{~K}$. For ${ }^{226} \mathrm{Ra}$, TBI was observed to have the lowest activity concentration while GSPPT had the highest values. Similarly, for ${ }^{232} \mathrm{Th}$, GPI recorded the lowest result while the highest value was recorded in RBI. Finally, BGI reported the highest activity concentration for ${ }^{40} \mathrm{~K}$, while the lowest result was noted in GPI. The mean results of the activity concentrations for ${ }^{226} \mathrm{Ra},{ }^{232} \mathrm{Th}$ and ${ }^{40} \mathrm{~K}$ were estimated to be 68.03 , 84.79 and $620.89 \mathrm{~Bq} / \mathrm{kg}$ respectively. The mean values reported in this study were found to be much higher by $1.95,2.83$ and 1.55 times than the world average standard values of 35,30 and 400 $\mathrm{Bq} / \mathrm{kg}$ respectively, according to [19] findings. The results slightly compares with [10], this may be as a result of the similarity in the regional geology of the areas where the raw materials were sourced. 
Table 2: Shows the activity concentration of ${ }^{238} \mathrm{U},{ }^{232} \mathrm{Th}$ and ${ }^{40} \mathrm{~K}$ in the present study

\begin{tabular}{lllll}
\hline $\mathbf{s} / \mathbf{n}$ & Sample ID & \multicolumn{2}{c}{ Activity Concentration $(\mathbf{B q} / \mathbf{k g})$} & \\
& & ${ }^{226} \mathrm{Ra}(\mathrm{Bq} / \mathrm{kg})$ & ${ }^{232} \mathrm{Th}(\mathrm{Bq} / \mathrm{kg})$ & ${ }^{40} \mathrm{~K}(\mathrm{~Bq} / \mathrm{kg})$ \\
\hline 1 & RBI & $94.47 \pm 0.5$ & $104.28 \pm 8.0$ & $785.77 \pm 15.0$ \\
2 & TBI & $18.68 \pm 0.6$ & $84.79 \pm 8.0$ & $670.45 \pm 15.0$ \\
3 & GVI & $80.9 \pm 0.5$ & $88.2 \pm 8.0$ & $460.9 \pm 15.0$ \\
4 & GPI & $41.9 \pm 0.6$ & $42.1 \pm 9.0$ & $181.4 \pm 15.0$ \\
5 & GSPPT & $98.3 \pm 0.5$ & $92.2 \pm 8.0$ & $551.9 \pm 15.0$ \\
6 & BGI & $81.51 \pm 0.5$ & $102.11 \pm 8.0$ & $871.0 \pm 15.0$ \\
7 & BPI & $60.45 \pm 0.5$ & $79.86 \pm 8.0$ & $824.78 \pm 15.0$ \\
& & & & \\
& Mean & $\mathbf{6 8 . 0 3} \pm \mathbf{0 . 5 0}$ & $\mathbf{8 4 . 7 9} \pm \mathbf{8 . 0}$ & $\mathbf{6 2 0 . 8 9} \pm \mathbf{1 5 . 0}$ \\
\hline
\end{tabular}

\subsection{Radiological Assessment}

\subsubsection{The Absorbed Dose Rate}

Equation (1), recommended and used by [20] and [1] was used to determine the absorbed dose rates from the obtained activity concentrations and the estimated results are shown in Table 3.

$\mathrm{D}\left(\mathrm{nGyh}^{-1}\right)=0.462 \mathrm{C}_{\mathrm{Ra}}+0.604 \mathrm{C}_{\mathrm{Th}}+0.0417 \mathrm{C}_{\mathrm{k}}<80 \mathrm{nGyh}^{-1}$

From the result presented in the Table below, it could be seen that all the results were far higher than the recommended standard of $80 \mathrm{nGy} / \mathrm{h}$ except for GPI which reported lower than the standard. The highest absorbed dose rate was reported in RBI while the lowest was noticed in GPI as presented in Table 3. The mean value of the absorbed dose rate was found to be 108.54 $\mathrm{nGy} / \mathrm{h}$. It could be seen that most of the Indian tiles available in Nigerian market have very high absorbed dose rate except for GPI, making the Indian tiles unsafe in this regard.

\subsubsection{Determination of Radium equivalent $\left(R a_{e q}\right)$}

The values of $\mathrm{Ra}_{\mathrm{eq}}$ in the samples studied in this research were estimated using equation (2) according to [1], [12], [20].

$$
\mathrm{Ra}_{\mathrm{eq}}=\mathrm{AC}_{\mathrm{RA}}+1.43 \mathrm{AC}_{\mathrm{Th}}+0.077 \mathrm{AC}_{\mathrm{K}}
$$

where $\mathrm{AC}_{\mathrm{RA}}, \mathrm{AC}_{\mathrm{Th}}$ and $\mathrm{AC}_{\mathrm{K}}$ are the activities concentration of ${ }^{226} \mathrm{Ra},{ }^{232} \mathrm{Th}$ and ${ }^{40} \mathrm{~K}$ measured in $\mathrm{Bq} / \mathrm{kg}$ respectively. The results of the radium equivalent activity obtained for the available Indian tiles in Nigeria varied between 116.15 and $304.09 \mathrm{~Bq} / \mathrm{kg}$ (Table 3). The highest value of radium equivalent was noted in RBI while the lowest value was measured in GPI respectively. The average value of the activity concentration for radium equivalent was estimated to be $237.09 \mathrm{~Bq} / \mathrm{kg}$. In all, it was observed that for all the Indian tiles in Nigeria, their radium equivalent values were not above the accepted standard of 370 $\mathrm{Bq} / \mathrm{kg}$ according to [12] and [20].

\subsubsection{Calculation of External Hazard Index $\left(H_{e x}\right)$}

The radiation hazard index from gamma ray due to ${ }^{226} \mathrm{Ra}$, ${ }^{232} \mathrm{Th}$ and ${ }^{40} \mathrm{~K}$ could be estimated by equation (3) which is the equation foe calculating the external hazard index [1].

$\mathrm{H}_{\mathrm{ex}}=\left(\mathrm{A}_{\mathrm{Ra}} / 370\right)+\left(\mathrm{A}_{\mathrm{Th}} / 259\right)+\left(\mathrm{A}_{\mathrm{K}} / 4810\right) \leq 1$

where,

$A_{\text {Ra }}, A_{T h}$ and $A_{K}$ are the average values of the activity concentrations of ${ }^{226} \mathrm{Ra},{ }^{232} \mathrm{Th}$ and ${ }^{40} \mathrm{~K}$ in $\mathrm{Bq} / \mathrm{kg}$ respectively. The standard recommended for the $\mathrm{H}_{\mathrm{ex}}$ is a value less than 1 and at most equal to 1 . From the result obtained, the $\mathrm{H}_{\mathrm{ex}}$ varied between 0.31 and 0.82 for both GPI and RBI respectively. In this case, all the available Indian tiles considered for this parameter had values that are acceptable and within the allowable standard (Table 3 ). The estimated mean value of the $\mathrm{H}_{\mathrm{ex}}$ obtained is 0.64 . Thus, the Indian tiles are regarded to be safe for use in building construction purposes as far as this health parameter is concerned [1] and [14].

\subsubsection{Internal Hazard Index Estimation $\left(H_{i n}\right)$}

The internal hazard index is a measure of how much radiation an occupant of a confined setting is exposed to. This is represented by $\mathrm{H}_{\text {in }}$ and it can be calculated with equation (4) [21]:

$H_{\text {in }}=\left(A_{\mathrm{Ra}} / 185\right)+\left(\mathrm{A}_{\mathrm{Th}} / 259\right)+\left(\mathrm{A}_{\mathrm{K}} / 4810\right) \leq 1$

where $A_{R a}, A_{T h}$ and $A_{K}$ are activity concentrations of ${ }^{226} \mathrm{Ra},{ }^{232} \mathrm{Th}$ and ${ }^{40} \mathrm{~K}$, respectively in $\mathrm{Bq} / \mathrm{kg}$. For a building construction material to be regarded as safe, the hazard index from the radiation emitted from such materials must be within a standard limit of less than or equal to 1 . The observed values of $\mathrm{H}_{\text {in }}$ for the Indian tiles in Nigeria were noted to range between 0.25 and 1.08 (Table 3).

The lowest value of $\mathrm{H}_{\text {in }}$ was reported by TBI while the highest value was noticed in RBI. BGI and RBI were noticed to be greater than the recommended world safe value of 1 among the Indian tiles investigated, which might be considered unsafe for internal usage purposes. The average value of the $\mathrm{H}_{\text {in }}$ was estimated to be 0.78 , which is within the recommended standard for use in building materials. The results presented in Table 3 agreed with [7] and [11]. 
Table 3: Presents the radium equivalent, dose rate, internal and external hazard indices

\begin{tabular}{llllll}
\hline $\mathbf{s} / \mathbf{n}$ & Sample ID & $\mathbf{D}_{\mathbf{R}}$ & $\mathbf{R a}_{\text {eq }}$ & $\mathbf{H}_{\text {ex }}$ & $\mathbf{H}_{\text {in }}$ \\
1 & RBI & 139.40 & 304.09 & 0.82 & 1.08 \\
2 & TBI & 87.80 & 191.55 & 0.52 & 0.25 \\
3 & GVI & 109.87 & 242.46 & 0.65 & 0.87 \\
4 & GPI & 52.35 & 116.15 & 0.31 & 0.43 \\
5 & GSPPT & 124.12 & 272.59 & 0.75 & 1.00 \\
6 & BGI & 135.65 & 294.65 & 0.79 & 1.02 \\
7 & BPI & 110.56 & 238.16 & 0.64 & 0.81 \\
& Mean & $\mathbf{1 0 8 . 5 4}$ & $\mathbf{2 3 7 . 0 9}$ & $\mathbf{0 . 6 4}$ & $\mathbf{0 . 7 8}$ \\
\hline
\end{tabular}

\subsubsection{The Annual Effective Dose Rate (AEDR)}

Equation (5) was used to estimate the AEDE received by occupants from the indoor internal dose rate according to [1].

$$
\mathrm{AEDR}=(0.49 \mathrm{CRa}+0.76 \mathrm{CTh}+0.048 \mathrm{CK}) \times 8.76 \times 10^{-3}
$$

The values of the AEDE ranged between 0.18 and $0.67 \mathrm{mSvy}^{-}$ ${ }^{1}$ with an average value of $0.50 \mathrm{mSvy}^{-1}$. The mean value from the Indian tiles being considered in this study was estimated to be lower than the world's recommended average value of $0.7 \mathrm{mSvy}^{-}$ ${ }^{1}$ [11]. The values of AEDR for each sample are presented in Table 4. The result obtained for AEDR in this study was observed to be higher than [9]. This is suspected to be as a result of difference in the geological formations of the materials used in the production of the tiles.

\subsubsection{Gamma Index Estimation (I $\gamma)$}

This index is engaged to calculate the hazrd of $\gamma$-radiation because of the presence of natural radionuclide in the samples being investigated. The gamma index (I $\gamma$ ) is evaluated using Equation (6) according to [22].

$\mathrm{I} \gamma=\mathrm{C}_{\mathrm{Ra}} / 300(\mathrm{~Bq} / \mathrm{kg})+\mathrm{C}_{\mathrm{Th}} / 200(\mathrm{~Bq} / \mathrm{kg})+\mathrm{C}_{\mathrm{K}} / 3000(\mathrm{~Bq} / \mathrm{kg})$
The results obtained from the equation above for the Indian tile samples are presented below. A range of values between 0.29 and 1.10 were obtained from the calculation of the gamma index (Table 4). The results revealed RBI to have the highest result with a value of 1.10 while TBI was noted to have the lowest result. The recommended safe limit for gamma index varied between 0.3 and $1 \mathrm{mSvy}^{-1}$, which is the extra gamma dose to the ones received outside of the building [23]. The calculated average I $\gamma$ obtained is 0.80 , which is less than the restricted limit by international standard. Thus, building materials such as tiles should not be considered for radioactivity if the excess gamma radiation emanating from them increases the annual effective dose of a member of the public by $0.3 \mathrm{mSv}$ at the most. Based on the recommended standard for gamma index, most of the Indian tiles in Nigeria are below the safety limit of $1 \mathrm{mSv}$ except RBI (1.10) and BGI (1.07).

\subsubsection{Determination of Alpha Index (I $\alpha)$}

The estimation of the alpha index is another essential part of hazard measurement that quantifies the amount of alpha radiation due to radon inhalation that has its source from building materials. The alpha index for the Indian tiles was determined using equation (7) $[24]$ and [25] is:

Table 4: Presents the AEDR, gamma activity and alpha ray indices.

\begin{tabular}{|c|c|c|c|c|c|}
\hline $\mathbf{s} / \mathbf{n}$ & Sample ID & $\begin{array}{l}\text { Annual Effective } \\
\text { AEDR }(\mathrm{mSv} / \mathrm{y})\end{array}$ & Dose & Gamma activity Index $\left(I_{\gamma}\right)$ & $\begin{array}{l}\text { Alpha Index } \\
\qquad\left(I_{\propto}\right)\end{array}$ \\
\hline 1 & RBI & 0.67 & & 1.10 & 0.47 \\
\hline 2 & TBI & 0.18 & & 0.29 & 0.06 \\
\hline 3 & GVI & 0.54 & & 0.86 & 0.40 \\
\hline 4 & GPI & 0.26 & & 0.41 & 0.21 \\
\hline 5 & GSPPT & 0.61 & & 0.97 & 0.49 \\
\hline 6 & BGI & 0.67 & & 1.07 & 0.41 \\
\hline \multirow[t]{2}{*}{7} & BPI & 0.54 & & 0.88 & 0.30 \\
\hline & Mean & 0.50 & & 0.80 & 0.33 \\
\hline
\end{tabular}


$\mathrm{I} \alpha=\mathrm{C}_{\mathrm{Ra}} / 200(\mathrm{~Bq} / \mathrm{kg})$

where $\mathrm{C}_{\mathrm{Ra}}(\mathrm{Bq} / \mathrm{kg})$ is defined according to [26], [25] and [21]. The Table above shows the values of the estimated alpha index from the Indian tiles that are available in Nigeria. It is observed that the upper boundary of the concentration of radon (I $\alpha)$ is same as 1 [27], [28] and [26]. In the present study, the obtained results revealed that the radon concentration varied from 0.06 to 0.49 with a mean value of 0.33 . TBI reported the lowest result while the highest value was noticed in GSPPT. The results obtained from the alpha index are far less than the recommended value. This implies that the exhalation of radon from all the investigated Indian tiles would amount in indoor concentration that is lower than $200 \mathrm{~Bq} / \mathrm{kg}$.

\section{Conclusion}

Seven imported Indian tiles available in Nigerian markets were investigated in this study to determine their radiological health hazards on users. The estimated radiological parameters such as the dose rate, radium equivalent, internal and external hazard indices, gamma index, annual effective dose and the corresponding alpha activity index were used to determine the potential health risks on people exposed to these tiles. The mean activity concentrations of ${ }^{226} \mathrm{Ra},{ }^{232} \mathrm{Th}$ and ${ }^{40} \mathrm{~K}$ were discovered to be 68.03 , 84.79 and $620.89 \mathrm{~Bq} / \mathrm{kg}$ respectively. These values reported higher than the recommended safe limit for building purposes. Similarly, the dose rate for tiles investigated ranged between 59.14 and 154.65. This revealed much higher values than the recommended standard except for GPI which recorded a lower result. However, the mean result of the radium activity equivalent in all the samples investigated was observed to be $237.09 \mathrm{~Bq} / \mathrm{kg}$ and it is much lower than the recommended safe limit. In the same way, the result of the external index varied between 0.31 and 0.82 . Likewise, the result of the internal hazard index ranged between 0.25 and 1.08 , with an average value of 0.78 . Moreover, the results of the annual effective dose were between 0.18 and 0.67 . Finally, the gamma activity and the alpha indices were estimated, their average values were found to be 0.80 and 0.33 respectively. All the above results are within the recommended safe limit for building tiles. Generally, the dose rate for Indian tiles are far higher than the recommended safe standard, but all other radiological parameters prove that the tiles are safe to be used for construction purposes in Nigeria. However, similar investigation is recommended to be conducted regularly in order to ascertain the safety of Nigerian consumers that depend largely on imported goods.

\section{Acknowledgement}

The authors wish to express gratitude to the management of Covenant University for funding this research under the grant scheme (No: CUCRID/VC/17/02/02/06-FS).

\section{Conflict of Interest}

There is no conflict of interest on this article.

\section{References}

[1] UNSCEAR. "Sources, Effects, and Risks of Ionizing Radiation," Report to the General Assembly, with Scientific Annexes, UN, New York, 2000.

[2] L. Yan, Q.V. Le, C. Sanne, et al. "Phytoremediation of radionuclides in soil, sediments and water," Journal of Hazardous Materials, 407, 2021, doi.org/10.1016/j.jhazmat.2020.124771

[3] N. Sharma, J. Singh, S.C. Esakki, and R.M. Tripathi, "A study of the natural radioactivity and radon exhalation rate in some cement used in India and its radiological significance,” J Radiat Res Appl Sci., 9(1), 47-56, 2016, doi.org/10.1016/j.jrras.2015.09.001

[4] IAEA, "Radiation in everyday life", www.iaea.org/publications/factsheets/english/radlife [accessed online on $15 / 12 / 2020]$

[5] F.J. Maringer, A. Baumgartner, F. Rechberger, C.Siedel, M. Stietka, "Activity measurement and effective dose modelling of natural radionuclides in building material," Applied Radiation and Isotopes, 81, 279-283, 2013, doi.org/10.1016/j.apradiso.2013.03.029

[6] H.H. Hussain, R.O. Hussain, R.M. Yousef, Q. Shamkhi, "Natural radioactivity of some local building materials in the middle Euphrates of Iraq," Journal of Radioanalytical and Nuclear Chemistry, 284, 43-47, 2010, doi.org/10.1007/s10967-010-0464-1

[7] E.S. Joel, O. Maxwell, O.O. Adewoyin, et al., "Assessment of natural radioactivity in various commercial tiles used for building purposes in Nigeria," MethodsX, 5, 18-19, 2018, doi.org/10.1016/j.mex.2017.12.002

[8] World Health Organization (WHO), "Handbook on indoor radon: a public health perspective," 2009.

[9] S. Elnobi, S. Harb, N.K. Ahmed, "Influence of grain size on radionuclide activity concentrations and radiological hazard of building material samples," Applied Radiation and Isotopes, 130, 43-48, 2017, doi.org/10.1016/j.apradiso.2017.09.021

[10] S. Abdullahi, A.F. Ismail, S. Samat, "Determination of indoor doses and excess lifetime cancer risks caused by building materials containing natural radionuclides in Malaysia," Nuclear Engineering and Technology, 51, 325336, 2019, doi.org/10.1016/j.net.2018.09.017

[11] O. Maxwell, O.O. Adewoyin, E.S. Joel et al., "Radiation exposure to dwellers due to naturally occurring radionuclides found in selected commercial building materials sold in Nigeria," Journal of Radiation Research and Applied Sciences, 11, 225-231, 2018, doi.org/10.1016/j.jrras.2018.01.007

[12] M. Gupta, R.P. Chauhan, "Estimation of Low-Level Radiation Dose from Some Building Materials Using Gamma Spectroscopy," Indoor Built Environ. 21(3), 465-73, 2012, doi.org/10.1177\%2F1420326X11414283

[13] S. Ali, M. Tufail, K. Jamil, A. Ahmad and H.A. Klian, "Gamma-ray activity and dose rate of brick samples from some areas of North West Frontier Province (NWFP), Pakistan," The Science of the Total Environment, 187(3), 247-252, 1996, doi.org/10.1016/0048-9697(96)05109-1

[14] M. Faheem, S.A. Mujahid, Matiullah. "Assessment of radiological hazards due to the natural radioactivity in soil and building material samples collected from six districts of the Punjab province-Pakistan," Radiation Measurement, 43, 1443-1447, 2008, doi.org/10.1016/j.radmeas.2008.02.014

[15] D. Ghosh, A. Deb, S. Bera, R. Sengupta and K.K. Patra "Assessment of alpha activity of building materials commonly used in West Bengal, India," Journal of Environmental Radioactivity, 99(2), 316-321, 2008, doi.org/10.1016/j.jenvrad.2007.08.002

[16] S. Turhan, U.N. Baykan, K. Sen, "Measurement of the natural radioactivity in building materials used in Ankara and assessment of external doses," J. Radiol. Prot., 28 (1), 83-91, 2008, doi.org/10.1088/0952-4746/28/1/005

[17] P. Chauhan, R.P. Chauhan, M. Gupta, "Estimation of naturally occurring radionuclides in fertilizers using gamma spectrometry and elemental analysis by XRF and XRD techniques," Microchemical Journal, 106, 73-78, 2013, doi.org/10.1016/j.microc.2012.05.007

[18] N. Damla, U. Cevik, A.I. Kobya, A. Celik, N. Celik, I. Yıldırım, "Assessment of natural radioactivity and mass attenuation coefficients of brick and roofing tile used in Turkey," Radiat. Meas., 46, 701-708, 2011, doi.org/10.1016/j.radmeas.2011.06.004

[19] International Atomic Energy Agency (IAEA), "Construction and use of calibration facilities for Radiometric Field Equipment," Technical Reports Series No.309, IAEA,Vienna, 1989.

[20] International Atomic Energy Agency (IAEA), "Extent of Environmental Contamination by Naturally Occurring Radioactive Material (NORM) and Technological Options for Mitigation," Technical Reports Series No. 419, STI/DOC/010/419. 2003

[21] UNSCEAR. Sources, Effects and Risks of Ionizing Radiations. United Nations, New York. 1998.

[22] J. Beretka, P.J. Mathew, "Natural radioactivity of Australian building materials, industrial waste sand by-products," Health Phys. 48, 87-95, 1985, doi.org/10.1097/00004032-198501000-00007

[23] OECD (Organization for Economic Co-operation and Development), 'Exposure to radiation from radioactivity in building materials,' Report by a group of experts of the OECD Nuclear Energy Agency, 1979.

[24] E.C., "Radiological protection principles concerning the natural radioactivity of building materials," Radiation Protection, 112. 1999. 
[24] S. Righi, L. Bruzzi, "Natural radioactivity and radon exhalation in building materials used in Italian dwellings," J. Environ. Radioact. 88, 158-170, 2006, doi.org/10.1016/j.jenvrad.2006.01.009

[25] L. Xinwei, W. Lingqing, J. Xiaodan, Y. Leipeng, D. Gelian, "Specific activity and hazards of Archeozoic-Cambrian rock samples collected from the Weibei area of Shaanxi, China," Radiat. Prot. Dosim. 118, 352-359, 2006, doi.org/10.1093/rpd/nci339

[26] ICRP, "Protection against Rn-222 at home and at work," ICRP publication 65, Ann ICRP, 23 (2), 1-48,1994.

[27] M. Tufail, A. Nasim, J. Sabiha, H. Tehsin, "Natural radioactivity hazards of building bricks fabricated from soil of two districts of Pakistan," Journal of Radiological Protection, 27, 481-492, 2007, doi.org/10.1088/0952$4746 / 27 / 4 / 009$ 